\title{
Association of sleep quality in Behcet disease with disease activity, depression, and quality of life in Korean population
}

\author{
Jimin Lee ${ }^{1, \star}$, Sung-Soo Kim ${ }^{2, \star}$, Hye-Jin Jeong ${ }^{1}$, Chang-Nam Son ${ }^{1}$, Ji-Min Kim ${ }^{1}$, Yong-Won Cho ${ }^{3}$, and \\ Sang-Hyon $\mathrm{Kim}^{1}$
}

\begin{abstract}
${ }^{1}$ Division of Rheumatology, Department of Internal Medicine, Keimyung University Dongsan Medical Center, Daegu; ${ }^{2}$ Division of Rheumatology, Department of Internal Medicine, Gangneung Asan Hospital, University of Ulsan College of Medicine, Gangneung; ${ }^{3}$ Department of Neurology, Keimyung University Dongsan Medical Center, Daegu, Korea
\end{abstract}

\author{
Received: November 12, 2016 \\ Revised : December 6, 2016 \\ Accepted: December 7, 2016

\section{Correspondence to} \\ Sang-Hyon Kim, M.D. \\ Division of Rheumatology, \\ Department of Internal Medicine, \\ Keimyung University Dongsan \\ Medical Center, 56 Dalseong-ro, \\ Jung-gu, Daegu 41931, Korea \\ Tel: +82-53-250-7414 \\ Fax: +82-53-250-7434 \\ E-mail: mdkim9111@dsmc.or.kr \\ *These authors contributed \\ equally to this work.
}

Background/Aims: Sleep disturbance is prime concern in patients with Behcet disease. The purpose of this study was to find out the effects of sleep quality, in Korean patients suffering from Behcet disease. We further investigated the relationship between depression, quality of life and the clinical findings of Behcet disease.

Methods: The study was performed by the cross-sectional design. Sleep quality was assessed by the Korean version of Pittsburgh sleep quality index (PSQI). Disease activity of Behcet disease was evaluated by Behcet disease current activity form (BDCAF). Depression was assessed by the Korean version of Beck depression inventory second edition (BDI-2). Quality of life was assessed by the Korean version of the Leeds Behcet disease quality of life measure (BDQoL).

Results: Among the 100 patients studied, $42 \%$ reported poor sleep quality (PSQI $\geq 9)$. These patients have a higher BDI-2, total BDCAF and pain visual analogue scale (VAS) score $(p<0.001, p=0.022$, and $p=0.005)$. Considering BDCAF, the frequency of genital ulcer was significantly higher $(p=0.01)$. Behcet was higher in females. The BDQoL was lower in poor sleeper group $(p=0.004$ and $p<0.001)$. Among 7 PSQI components, daytime dysfunction was higher in patients with high disease activity $(p=0.03)$. Total PSQI score were strongly correlated with BDCAF, BDI-2, BDQoL, and pain VAS score $(p=0.02, p<0.001, p<0.001$, and $p<0.001$, respectively).

Conclusions: Low sleep quality is directly associated with disease activity, depression, and quality of life in Korean patients with Behcet disease.

Keywords: Behcet syndrome; Sleep quality

\section{INTRODUCTION}

Behcet disease is a chronic and systemic vasculitis of unknown origin affecting blood vessels of any size [1]. Clinical manifestation of Behcet disease is very diverse, and involves the mucous membranes, eyes, blood vessels, joints, gastrointestinal tract, urogenital, respira- tory, nervous system, etc. These complex and varied symptoms are continuously in a cycle of remissions and recurrences, resulting in difficulty to predict progress of the disease. These problems also cause restrictions on personal life, and many patients have associated psychiatric problems.

Various studies concerning sleep quality and Behcet 
disease have been done. Turkish studies reported the sleep quality in Behcet disease is very poor, and restless legs syndrome, fatigue, depression, anxiety, and activity of Behcet disease could affect to the quality of life [2]. Other studies report that fibromyalgia is a commonly occurring syndrome in Behcet disease, and showed a significant relationship with depression and anxiety; however, they were not related with disease activity $[3,4]$.

Previously, we compared and evaluated the sleep quality, quality of life, depression, and disease activity in rheumatoid arthritis (RA) patients [5] and ankylosing spondylitis patients [6]. A significant relationship between disease activity and sleep quality was observed. However, to date, there have been limited studies regarding sleep quality, quality of life, and depression in Behcet disease patients for Korean population. Extrapolating that Behcet disease, a kind of RA, also affects the sleep quality, it is considered a meaningful study to compare and analyze the relationship between disease activity and sleep quality, quality of life, and depression in Korean population of Behcet disease patients.

\section{METHODS}

\section{Study population}

Study participants were enrolled from February 2014 to July 2015. A total of 100 patients with Behcet disease, who visited two selected rheumatology clinic centers in Korea, were enrolled.

Inclusion criteria for patient group were adults 19 years or more, and who met the diagnostic criteria proposed at the International Study Group of Behcet disease [7]. Exclusion criteria were patients who were uneducated and unable to answer the questionnaire, had a low mental aptitude, a medical disease history like malignant tumor or infection, or who were suspected to be drug addicts (including sleeping pills or alcohols).

\section{Ethics statement}

This study was approved by Institutional Review Board (IRB) at the university hospital where the study was conducted. (IRB number: 2014-07-017).

\section{Assessment of clinical variables}

Along with the questionnaire, face-to-face interviews were conducted with the Behcet disease patients. Age, gender, body mass index, other associated disease history, and the kind, frequency of smoking and caffeine consumptions, social-economic status, and demographic information (such as accompanying residents) were investigated. Sleep quality, quality of life (QoL), depression, fibromyalgia, and disease activity of Behcet disease were also scrutinized from the questionnaire. Through the medical records, additional investigation were conducted, such as blood test for C-reactive protein (CRP) and erythrocyte sedimentation rate (ESR), disease duration, and medical history associated with Behcet disease.

\section{Assessment of sleep quality}

Quality of sleep was evaluated using the Korean version of the Pittsburgh sleep quality index (PSQI). PSQI consists of questionnaires regarding sleep habits over the past 1 month, and is a useful test to evaluate the sleep quality.

It contains seven subsections: subjective sleep quality, sleep latency, sleep duration, habitual sleep efficiency, sleep disturbances, use of sleeping medication, and daytime dysfunction. Each of these components has a range of $\mathrm{o}$ to 3 points, with a total adding up in the ranges $\mathrm{o}$ to 21 points. Higher scores indicate poor sleep quality; when total score is more than 9, they are defined as the poor sleeper group [8].

\section{Assessment of life quality}

QoL was evaluated using the Korean version of the Leeds Behcet disease quality of life measure (BDQoL). This tool consists of 30 components regarding QoL with Yes/No answer. Each component has a range of o to 1 points, and the lower scores indicate worse QoL as based on a maximum of 30 points [9].

\section{Assessment of depression}

Korean version of the Beck depression inventory second edition (BDI-2) was used to evaluate the degree of depression.

BDI-2 consists of 21 multiple-choice self-report inventory, with points ranging from o to 3 . By adding the scores of each components, a range from o to 63 points are assessed. Higher scores indicate severe depression, and 20 points are defined as cut-off point for depression [10]. 


\section{Assessment of Behcet disease activity}

Behcet disease current activity form (BDCAF) was evaluated as an indicator of Behcet disease activity. To assess the disease activity, we used the English version of BDCAF, first designed in 1999 and amended once in 2006.

Depending on the presence of symptom which patients complained of during the past 1 month, the score is measured as o to 1 points, with the total adding up in the range o to 12. Each component consists of headache, oral ulcer, genital ulcer, erythema, skin pustule, arthritis, arthralgia, nausea/vomiting/abdominal pain, diarrhea or frank blood per rectum, new symptoms in eye, new symptoms in nervous system, and new symptoms in major vessels. When the total score is higher than 5 points, it is defined as the high active Behcet disease patients group [11].

\section{Assessment of fibromyalgia and pain}

Fibromyalgia is a chronic systemic pain disorder, and it usually accompanies chronic fatigue, sleep disturbance, depression, etc. It is usually associated with inflammatory autoimmune disease such as RA, systemic lupus erythematous, or Behcet disease. From the fibromyalgia questionnaire survey, the degree of fibromyalgia was investigated, and the degree of pain was measured by visual analogue scale (VAS), which is the patient global assessment for Behcet disease, and indicated from o to 100 score for the extent of patients' feeling.

\section{Statistical analysis}

The statistical program SPSS version 20.0 (IBM Co., Armonk, NY, USA) was used for data processing and statistical analysis. Patients were presented as number and percentage for each assessment, and continuous variable results were presented as medium values and interquartile using a $t$ test. According to the presence of Behcet disease activity and sleep disturbance, variables were compared in the two groups, and Mann-Whitney $U$ test was used for analysis. By setting the Behcet disease activity as a continuous variable, Spearman correlation coefficients were used to examine the correlations between the factors which associated with Behcet disease activity such as BDI-2, BDQoL, total PSQI, and subsection PSQI. Logistic regression analysis was performed to detect the independent risk factors for the occurrence of sleep disturbance. In the analysis, each factor was an
Table 1. Demographic and clinical characteristics of Behcet disease patients

\begin{tabular}{|c|c|}
\hline Variable & Value \\
\hline Mean age, yr & $51(44 \cdot 5-56.0)$ \\
\hline Female sex & 69 \\
\hline Mean BMI, kg/m² & $22.4(20.5-24.4)$ \\
\hline \multicolumn{2}{|l|}{ Employment status } \\
\hline None & 45 \\
\hline Part time & 11 \\
\hline Full time & 44 \\
\hline \multicolumn{2}{|l|}{ Living circumstances } \\
\hline Alone & 9 \\
\hline Partner & 91 \\
\hline Disease duration, mon & $77.5(24.0-136.0)$ \\
\hline \multicolumn{2}{|l|}{ Concurrent consumptions } \\
\hline Caffeine & 89 \\
\hline Alcohol & 28 \\
\hline \multicolumn{2}{|l|}{ Comorbidities } \\
\hline Hypertension & 13 \\
\hline Osteoarthritis & 12 \\
\hline Diabetes mellitus & 6 \\
\hline Thyroid disease & 6 \\
\hline Atrial flutter & 1 \\
\hline Chronic obstructive lung disease & 1 \\
\hline Mean ESR, mm/hr & $15.0(7.0-25.0)$ \\
\hline Mean CRP, mg/dL & $0.1(0.0-0.3)$ \\
\hline Mean prednisolone dose, $\mathrm{mg}$ & $2.5(2.0-5.0)$ \\
\hline Mean prednisolone duration, mon & $11.0(8.0-22.0)$ \\
\hline \multicolumn{2}{|l|}{ Current BD medication } \\
\hline Prednisolone & 90 \\
\hline Methotrexate & 5 \\
\hline Hydroxyquinolone & 7 \\
\hline Sulfasalazine & 18 \\
\hline Mizoribine & 3 \\
\hline Tacrolimus & 1 \\
\hline Azathioprine & 13 \\
\hline Cyclosporine & 6 \\
\hline Poor sleepers & 42 \\
\hline Mean PSQI score & $7.0(4.5-11.5)$ \\
\hline Fibromyalgia & 28 \\
\hline Mean VAS score & $30.0(20.0-55.0)$ \\
\hline Mean BDCAF & $3.0(2.0-4.0)$ \\
\hline Active BD patients & 17 \\
\hline
\end{tabular}

Values are presented as percentage or median (range). BMI, body mass index; ESR, erythrocyte sedimentation rate; CRP, C-reactive protein; BD, Behcet disease; PSQI, Pittsburgh sleep quality index; VAS, visual analogue scale; BDCAF, Behcet disease current activity form. 
independent variable, and the total PSQI was a dependent variable. All the results with $p$ value less than 0.05 considered to be significant.

\section{RESULTS}

\section{Demographic and clinical characteristics of Behcet patients}

The median age of Behcet disease patients was 51 years, with a higher percentage reported in women (69\%). Among the favorite foods, caffeine consumption was $86 \%$, alcohol $28 \%$, and smoking $13 \%$. Economic activity and residential status for the patients were also investigated. The proportion of unemployed worker, part time worker, and full time worker was $45 \%, 11 \%$, and $44 \%$, respectively. As per the living status, $9 \%$ were living alone and $91 \%$ were living with family. In all, $20 \%$ had other associated disease, including hypertension, osteoarthritis, thyroid disease (hypothyroidism and hyperthyroidism), diabetes, chronic obstructive pulmonary disease, and atrial fibrillation. The average duration of Behcet disease was 77.5 months, and the average amount and period of steroid use were $2.5 \mathrm{mg}$ and 11 months, respectively. The median of CRP and ESR were within the normal range of 0.1 and 15.0, respectively. Amongst the 100 patients, poor sleeper group were 42 patients (42\%) and the patients who met the criteria for fibromyalgia were 28 (Table 1).

\section{Comparison between good sleeper and poor sleeper group}

In the poor sleeper group (PSQI $\geq 9$ ), the percentage of women and fibromyalgia were significantly higher at $34 \%$ and $24 \%$, respectively ( $p=0.004, p<0.001$ ). BDCAF, BDI-2, pain VAS were significantly higher in the group with sleep disturbance $(p=0.022, p=0.005, p<0.001$, respectively) and BDQoL was lower $(p<0.001)$. Among the BDCAF subsection, the frequency of genital ulcer was significantly higher in the group with poor sleep quality $(p=0.01)$. There were no significant differences between the two groups with regards to CRP, ESR, drug consumption, disease duration, age, living status, and economic activity sections (Table 2).

\section{Comparison according to Behcet disease activity}

The proportion of high disease activity in Behcet disease patients group (BDCAF > 5) was $17 \%$, and the duration of disease and prednisolone used were significantly shorter $(p=0.008, p=0.032$ ). The proportion with fibromyalgia in patients, pain VAS, and BDI-2 were significantly higher $(p<0.001, p=0.005, p=0.008$, respectively), and the BDQoL was significantly lower $(p=0.04)$. In the analysis of total PSQI and subsection PSQI, daytime dysfunction was significantly higher with higher disease activity $(p=0.03)$ (Table 3$)$.

\section{Correlation and regression analysis}

From the results of Spearman analysis, significant correlation is observed between total PSQI and VAS, BDI-2, and BDQoL, with the correlation coefficients being 0.35 , 0.52 , and -0.45 , respectively $(p<0.01)$. BDCAF showed significant correlation, having a correlation coefficient of $0.23(p<0.05)$. Sleep disturbance and daytime dysfunction also showed significant correlation with the VAS, BDI-2, BDQoL, and BDCAF. Use of sleep medication significantly correlated with the BDI-2 and BDQoL. The other factors for PSQI, which include sleep latency, habitual sleep efficiency, sleep duration, and subjective sleep quality, were positively correlated to VAS and BDI2, and negatively to BDQoL. In addition, the patient's age, duration of disease, ESR, CRP did not show statistically significant correlation with PSQI (Table 4).

Through logistic regression analysis, sex, pain VAS score, fibromyalgia, BDI-2, and BDQoL were set as independent variables. Regression analysis showed that BDCAF was significant risk factors for sleep disturbance (Table 5).

\section{DISSCUSION}

According to our study, the group with sleep disturbance had a higher degree of pain, depression, and disease activity, with significantly lower quality of life. Recently, along with the aging of the population and the increasing the number of patients who are suffering from chronic diseases, modern healthcare reveals that the mental and social health are closely associated with physical health, and their importance is gradually increasing. In psychosocial health, sleep quality, QoL, and 
Table 2. Comparison between good sleeper and poor sleeper group

\begin{tabular}{|c|c|c|c|}
\hline Variable & Good sleeper $(\mathrm{n}=58)$ & Poor sleeper $(n=42)$ & $p$ value \\
\hline Female sex & $35(60.3)$ & $34(81.0)$ & $0.004^{\mathrm{a}}$ \\
\hline Age, yr & $51.0(44.0-57.0)$ & $51.0(46.0-55.0)$ & 0.507 \\
\hline $\mathrm{BMI}, \mathrm{kg} / \mathrm{m}^{2}$ & $23.0(21.6-24.3)$ & $22.0(20.4-24.4)$ & 0.349 \\
\hline Disease duration, mon & $79.0(24.0-169.0)$ & $73.0(30.0-131.0)$ & 0.655 \\
\hline $\mathrm{ESR}, \mathrm{mm} / \mathrm{hr}$ & $14.0(5.0-24.0)$ & $16.5(10.0-27.0)$ & 0.206 \\
\hline $\mathrm{CRP}, \mathrm{mg} / \mathrm{mL}$ & $0.1(0.0-0.5)$ & $0.1(0.0-0.2)$ & 0.675 \\
\hline Prednisolone dose, mg & $2.5(2.0-5.0)$ & $3.2(2.0-5.0)$ & 0.889 \\
\hline Prednisolone duration, mon & $10.0(7.0-21.0)$ & $14.0(9.0-22.0)$ & 0.166 \\
\hline VAS & $30.0(10.0-50.0)$ & $50.0(30.0-70.0)$ & $0.005^{\mathrm{a}}$ \\
\hline Fibromyalgia & $4(3.0)$ & $24(40.3)$ & $0.000^{\mathrm{a}}$ \\
\hline BDI-2 & $8.0(4.0-13.0)$ & $19.0(9.0-23.0)$ & $0.000^{\mathrm{a}}$ \\
\hline BDQoL & $25(20.0-28.0)$ & $18.5(13.0-23.0)$ & $0.000^{\mathrm{a}}$ \\
\hline \multicolumn{4}{|l|}{ BDCAF } \\
\hline Total score & $2.0(1.0-4.0)$ & $3.0(2.0-4.0)$ & $0.022^{b}$ \\
\hline Headache & $11(19)$ & $16(38.1)$ & 0.058 \\
\hline Oral ulcer & $41(70.7)$ & $34(81)$ & 0.349 \\
\hline Genital ulcer & $7(12.1)$ & $15(35 \cdot 7)$ & $0.010^{\mathrm{b}}$ \\
\hline Erythema & $12(20.7)$ & $7(16.7)$ & 0.804 \\
\hline Skin pustule & $7(12.1)$ & $5(11.9)$ & 1.000 \\
\hline Arthritis & $16(27.6)$ & $15(35 \cdot 7)$ & 0.517 \\
\hline Arthralgia & $9(27 \cdot 3)$ & $33(49 \cdot 3)$ & 0.445 \\
\hline Eye symptoms & $9(15 \cdot 5)$ & $9(21.4)$ & 0.620 \\
\hline Nausea/Vomit/Abdominal pain & $10(17.2)$ & $7(16.7)$ & 1.000 \\
\hline Diarrhea/Blood per rectum & $7(12.1)$ & $1(2.4)$ & 0.165 \\
\hline Major vessel involvement & $2(3.4)$ & $6(14 \cdot 3)$ & 0.110 \\
\hline Nerve involvement & $8(13.8)$ & $9(21.4)$ & 0.463 \\
\hline
\end{tabular}

Values are presented as number (\%) or median (range).

BMI, body mass index; ESR, erythrocyte sedimentation rate; CRP, C-reactive protein; VAS, visual analogue scale; BDI-2, Korean version of the Beck depression inventory second edition; BDQoL, Korean version of the Leeds Behcet disease quality of life measure; BDCAF, Behcet disease current activity form.

${ }^{\mathrm{a}} p<0.01 .{ }^{\mathrm{b}} \mathrm{p}<0.05$.

depression could be important factors. The frequency of patients with sleep disturbances in Korean population is known to be about 5\% [12], and it has been reported that sleep disturbance is reported in various chronic disease patients, such as chronic renal failure [13] and restless legs syndrome [14]. Rheumatoid disease is one of chronic diseases; various studies done worldwide have reported that sleep disturbance is a common associate in RA [5,15] or ankylosing spondylitis patients [6]. The foreign researches also studied the relationship between
Behcet disease and sleep disturbance. However, the results did not indicate a significant impact on sleep quality with respect to the disease activity and severity; the studies mainly focused on comparing the sleep quality in Behcet disease patients and healthy volunteers [10-12]. Also, since the domestic research on the sleep quality of Korean Behcet disease is limited, we planned to undertake this study.

Behcet disease is a chronic and systemic disorder affecting multiple organs with a generalized angiitis of 
Table 3. Comparison according to Behcet disease activity

\begin{tabular}{|c|c|c|c|}
\hline Variable & $\mathrm{BDCAF} \leq 5(\mathrm{n}=83)$ & $\mathrm{BDCAF}>5(\mathrm{n}=17)$ & $p$ value \\
\hline Age, yr & $51.0(44.0-56.0)$ & $49.0(46.0-56.0)$ & 0.810 \\
\hline $\mathrm{BMI}, \mathrm{kg} / \mathrm{m}^{2}$ & $22.7(20.7-24.4)$ & $21.6(20.3-25.6)$ & 0.330 \\
\hline Employment status & & & 0.390 \\
\hline None & $35(42.2)$ & $10(58.8)$ & \\
\hline Part time & $9(10.8)$ & $2(11.8)$ & \\
\hline Full time & $39(47.0)$ & $5(29 \cdot 4)$ & \\
\hline Living circumstances & & & 0.360 \\
\hline Alone & $6(7.2)$ & $3(17.6)$ & \\
\hline Partner & $77(91.8)$ & $14(82.4)$ & \\
\hline Caffeine & $28(90.3)$ & $61(88.4)$ & 0.100 \\
\hline Alcohol & $15(48.4)$ & $13(18.8)$ & 0.080 \\
\hline Smoking & $12(14 \cdot 5)$ & $1(5 \cdot 9)$ & 0.570 \\
\hline Disease duration, mon & $90.0\left(35 \cdot 5^{-147.0}\right)$ & $30.0(16.0-55.0)$ & $0.008^{\mathrm{a}}$ \\
\hline Prednisolone dose, mg & $2.5(2.0-4.5)$ & $4.0(2.0-7.5)$ & 0.160 \\
\hline Prednisolone duration, mon & $12.0(8.0-24.0)$ & $9.0(8.0-10.0)$ & $0.030^{\mathrm{b}}$ \\
\hline $\mathrm{ESR}, \mathrm{mm} / \mathrm{hr}$ & $15.0(7.0-25.5)$ & $16.0(6.0-22.0)$ & 0.650 \\
\hline $\mathrm{CRP}, \mathrm{mg} / \mathrm{dL}$ & $0.1(0.0-0.3)$ & $0.0(0.0-0.1)$ & $0.020^{b}$ \\
\hline PSQI total score & $7.0(4.0-11.0)$ & $10.0(6.0-12.0)$ & 0.114 \\
\hline Sleep latency & $1.46(0.2-2.6)$ & $1.88(0.8-3.2)$ & 0.170 \\
\hline Sleep duration & $1.57(0.39-2.6)$ & $1.65(0.0-2.0)$ & 0.770 \\
\hline Sleep efficiency & $0.98(0.0-2.8)$ & $0.59(0.0-2.0)$ & 0.230 \\
\hline Sleep disturbance & $1.17(0.3-2.3)$ & $1.41(0.6-2.2)$ & 0.160 \\
\hline Sleep medication & $0.37(0.0-1.3)$ & $0.41(0.0-3.0)$ & 0.880 \\
\hline Sleep quality & $1.46(0.1-2.3)$ & $1.82(0.8-2.7)$ & 0.110 \\
\hline Daytime dysfunction & $1.02(0.2-2.0)$ & $1.71(0.1-2.9)$ & $0.030^{\mathrm{b}}$ \\
\hline VAS & $30.0(10.0-50.0)$ & $50.0(30.0-80.0)$ & $0.005^{\mathrm{a}}$ \\
\hline BDI-2 & $10.0(5.0-18.0)$ & $19.0(15.0-24.0)$ & $0.008^{a}$ \\
\hline BDQOL & $23.0(16.5-27.0)$ & $18.0(14.0-24.0)$ & $0.040^{b}$ \\
\hline
\end{tabular}

Values are presented as number (\%) or median (range).

BDCAF, Behcet disease current activity form; BMI, body mass index; ESR, erythrocyte sedimentation rate; CRP, C-reactive protein; PSQI, Pittsburgh sleep quality index; VAS, visual analogue scale; BDI-2, Korean version of the Beck depression inventory second edition; BDQoL, Korean version of the Leeds Behcet disease quality of life measure.

${ }^{\mathrm{a}} p<0.01 .{ }^{\mathrm{b}} p<0.05$.

arteries and veins [1], and the cause was not clearly revealed until now. The progression of Behcet disease is unpredictable as the remissions and recurrences appear as a continuous cycle. Mental stress is a known reason which causes worsening of the disease, and the symptoms may appear as deterioration of joint pain and eye symptoms [16]. Yazmalar et al. [17] reported the relationship between sleep quality in Behcet disease patients, and genital ulcers or arthritis. This study also demonstrated the score of BDCAF which showed the disease activity was higher in poor sleeper group, and the frequency of genital ulcers was higher among the 12 subsections. These symptoms from the deterioration of Behcet disease accompanied pain to the patient. In our study, the disease activity and pain showed significant positive correlations in most of PSQI sections.

Depression is the most common mental disorder in general adults, and it is well known to be accompanied 
Table 4. Correlation coefficients between components of PSQI and demographic and disease-related variables

\begin{tabular}{|c|c|c|c|c|c|c|c|c|}
\hline Variable & Total PSQI & $\begin{array}{c}\text { Sleep } \\
\text { latency }\end{array}$ & $\begin{array}{c}\text { Sleep } \\
\text { efficiency }\end{array}$ & $\begin{array}{c}\text { Sleep } \\
\text { duration }\end{array}$ & $\begin{array}{c}\text { Sleep } \\
\text { disturbance }\end{array}$ & $\begin{array}{c}\text { Sleep } \\
\text { medication }\end{array}$ & $\begin{array}{c}\text { Daytime } \\
\text { dysfunction }\end{array}$ & $\begin{array}{l}\text { Sleep } \\
\text { quality }\end{array}$ \\
\hline Age & 0.02 & -0.07 & -0.120 & -0.049 & -0.156 & -0.036 & -0.074 & -0.045 \\
\hline $\begin{array}{l}\text { Disease } \\
\text { duration }\end{array}$ & -0.09 & -0.02 & -0.035 & -0.060 & -0.145 & -0.115 & -0.012 & -0.103 \\
\hline CRP & -0.105 & -0.137 & -0.003 & -0.019 & -0.095 & -0.028 & -0.132 & -0.005 \\
\hline ESR & 0.079 & -0.002 & -0.130 & -0.019 & -0.068 & -0.090 & -0.065 & -0.181 \\
\hline VAS & $0.35^{\mathrm{a}}$ & $0.21^{b}$ & $0.28^{b}$ & $0.25^{b}$ & $0.28^{b}$ & 0.03 & $0.28^{b}$ & $0.36^{\mathrm{a}}$ \\
\hline BDI-2 & $0.52^{a}$ & $0.43^{\mathrm{a}}$ & $0.34^{\mathrm{a}}$ & $0.36^{\mathrm{a}}$ & $0.29^{\mathrm{a}}$ & $0.23^{b}$ & $0.28^{b}$ & $0.5^{\mathrm{a}}$ \\
\hline BDQoL & $-0.45^{\mathrm{a}}$ & $-0.36^{a}$ & $-0.33^{\mathrm{a}}$ & $-0.29^{\mathrm{a}}$ & $-0.31^{\mathrm{a}}$ & $-0.2^{b}$ & $-0.3^{\mathrm{a}}$ & $-0.39^{\mathrm{a}}$ \\
\hline BDCAF & $0.23^{\mathrm{b}}$ & 0.17 & 0.09 & 0.12 & $0.21^{b}$ & 0.1 & $0.26^{b}$ & 0.17 \\
\hline
\end{tabular}

PSQI, Pittsburgh sleep quality index; CRP, C-reactive protein; ESR, erythrocyte sedimentation rate; VAS, visual analogue scale; BDI-2, Korean version of the Beck depression inventory second edition; BDQoL, Korean version of the Leeds Behcet disease quality of life measure; BDCAF, Behcet disease current activity form.

${ }^{\mathrm{a}} \mathrm{p}<0.01 .{ }^{\mathrm{b}} \mathrm{p}<0.05$.

Table 5. Univariate logistic regression analysis between PSQI and BDCAF as a continuous variable

\begin{tabular}{lcc}
\hline \multirow{2}{*}{ Variable } & \multicolumn{2}{c}{ PSQI } \\
\cline { 2 - 3 } & OR $(95 \% \mathrm{CI})$ & p value \\
\hline BDCAF & $1.34(1.007-1.776)$ & 0.045 \\
\hline
\end{tabular}

PSQI, Pittsburgh sleep quality index; BDCAF, Behcet disease current activity form; OR, odds ratio; CI, confidence interval.

by various chronic diseases. Some domestic studies have reported up to $50.9 \%$ of RA patients have accompanying depression. In our study, the proportion of patients with depression was $46 \%$. Based on the previous studies that depression and sleep disturbance have positive correlations in general population or other patients, we included depression as an important risk factor. Yazmalar et al. [17] evaluated the degree of depression in Behcet disease patients using Hospital Anxiety and Depression Scale, and reported total PSQI and seven subsections had significant correlation with depression. Similar to previous studies, our study showed significantly higher BDI-2 score in poor sleeper group, and significant correlations in total PSQI and every subsection. Also, the higher disease activity group showed a significantly higher BDI-2 score.

Pain, depression and sleep disorders due to chronic disease were eventually results in lowering the quality of life. Ertam et al. [18] investigated the QoL of Behcet disease patients using SF-36 and WHOQOL-10o. They reported that their QoL deteriorated by activity of disease, and arthritis, ocular symptoms, or major vessels, and the disorder had a significant correlation with the degradation of QoL.

A variety of tools have been developed for evaluating the quality of life, and the Leeds BDQoL as self-testing format and developed by Gilworth et al. [4] is effectively used to evaluate the QoL of Behcet disease patients. In our study results from BDQoL, QoL deteriorated in the sleep disturbance group and high disease activity group, and had a significant correlation with every section of PSQI. This suggests that the QoL of the patient can be improved by maintaining low the disease activity of Behcet disease.

There are various limitations to this study. Firstly, the study was only carried out for total of 100 patients enrolled in the university hospital outpatient department, and a small number of cases cannot represent the whole Behcet disease. Secondly, the average inflammation levels which could objectively compare the disease itself, such as CRP and ESR, were o.1 as normal ranges, and drugs consumed, including prednisolone, did not vary. Third, until recently, the standard to divide the presence or absence of disease activity of Behcet disease was not generally established. A criteria to decide disease activity of Behcet disease is yet to be established, similar to DAS-28 (Disease Activity Score 28) for disease activity of RA, or BASDAI (Bath Ankylosing Spondylitis Disease 
Activity Index) to assess for disease activity of ankylosing spondylitis. It will be easier to plan the various studies more precisely and segmentally, once such a criteria is established. However, this study is significant to study the sleep disturbance, QoL, depression, and the other related factors in Korean Behcet disease patients for the first time and reveal their correlations.

\section{KEY MESSAGE}

1. Low sleep quality is related with high disease activity, depression and low quality of life in Korean Behcet disease patients.

2. Better disease control will improve the sleep quality of the patients.

\section{Conflict of interest}

No potential conflict of interest relevant to this article was reported.

\section{Acknowledgments}

The authors thank Prof. Eun-So Lee, Departments of Dermatology, Ajou University School of Medicine, for permitting using BDQoL-K for this study.

\section{REFERENCES}

1. Behcet $H$. Uber rezidivierende, aphthous durch ein virus verursachte geschwure am mund, am auge und an den genitalien. Dermatol Wochenschr 1937;105:1152-1157.

2. Uygunoglu U, Benbir G, Saip S, Kaynak H, Siva A. A polysomnographic and clinical study of sleep disorders in patients with Behcet and neuro-Behcet syndrome. Eur Neurol 2014;71:115-119.

3. Tascilar NF, Tekin NS, Ankarali H, et al. Sleep disorders in Behcet's disease, and their relationship with fatigue and quality of life. J Sleep Res 2012;21:281-288.

4. Gilworth G, Chamberlain MA, Bhakta B, Haskard D, Silman A, Tennant A. Development of the BD-QoL: a quality of life measure specific to Behcet's disease. J Rheumatol 2004;31:931-937.

5. Son CN, Choi G, Lee SY, et al. Sleep quality in rheumatoid arthritis, and its association with disease activity in a
Korean population. Korean J Intern Med 2015;30:384-390.

6. Jeong HJ, Lee TH, Lee JM, et al. Sleep disturbances in Korean patients with ankylosing spondylitis are associated with increased disease activity. J Rheum Dis 2014;21:241247.

7. International Study Group for Behcet's Disease. Criteria for diagnosis of Behcet's disease. Lancet 1990;335:10781080.

8. Sohn SI, Kim DH, Lee MY, Cho YW. The reliability and validity of the Korean version of the Pittsburgh Sleep Quality Index. Sleep Breath 2012;16:803-812.

9. Yi SW, Kim JH, Lim KY, Bang D, Lee S, Lee ES. The Behcet's Disease Quality of Life: reliability and validity of the Korean version. Yonsei Med J 2008;49:698-704.

10. Lim SY, Lee EJ, Jung SW, et al. The validation study of Beck Depression Scale 2 in Korean version. Anxiety Mood 2011;7:48-53.

11. de Souza Neves F, Caldas CA, de Medeiros DM, de Moraes JC, Goncalves CR. Adaptacao transcultural da versao simplificada (s) do Behcet's Disease Current Activity Form (BDCAF) e comparacao do desempenho das versoes brasileiras dos dois instrumentos de avaliacao da atividade da Doenca de Behcet: BR-BDCAF e BR-BDCAF(s). Rev Bras Reumatol 2009;49:20-31.

12. Ohayon MM, Hong SC. Prevalence of insomnia and associated factors in South Korea. J Psychosom Res 2002;53:593-600.

13. Cho YW, Lee H, Lee JH, Han SY, Lee MY. Sleep disorders in maintenance dialysis patients with end-stage renal disease. J Korean Neurol Assoc 2003;21:492-497.

14. Hong SY, Lee JH, Cho YW. Quality of life in patients with restless legs syndrome in Korea: comparison with other chronic diseases. J Korean Neurol Assoc 2010;28:257-262.

15. Westhovens R, Van der Elst K, Matthys A, Tran M, Gilloteau I. Sleep problems in patients with rheumatoid arthritis. J Rheumatol 2014;41:31-40.

16. Tanriverdi N, Taskintuna, Duru C, Ozdal P, Ortac S, Firat E. Health-related quality of life in Behcet patients with ocular involvement. Jpn J Ophthalmol 2003;47:85-92.

17. Yazmalar L, Batmaz I, Sariyildiz MA, et al. Sleep quality in patients with Behcet's disease. Int J Rheum Dis 2014 Sep 8 [Epub]. http://doi.org/10.1111/1756-185X.12459.

18. Ertam I, Kitapcioglu G, Aksu K, et al. Quality of life and its relation with disease severity in Behcet's disease. Clin Exp Rheumatol 2009;27(2 Suppl 53):S18-S22. 